www.jmscr.igmpublication.org

Index Copernicus Value: 79.54

ISSN (e)-2347-176x ISSN (p) 2455-0450

crossref DOI: https://dx.doi.org/10.18535/jmscr/v7i3.219

\title{
A Study of Coronary Risk and LDL in Type II Diabetic Patients
}

\author{
Authors \\ M.Ramanathan $^{1^{*}}$, M.F. Mohamed Azath Ali ${ }^{2}$, S.M.Rajeswari ${ }^{3}$ \\ ${ }^{1}$ Assistant Professor, Dept. of General Medicine, Govt KAPV Medical College, Tiruchirapalli \\ ${ }^{2}$ M.D Gen Medicine Consultant Physician K.G Multispeciality Hospital, Thanjavur \\ ${ }^{3}$ M.B.B.S, VMKV Medical College, Salem \\ *Corresponding Author \\ Dr M. Ramanathan
}

Assistant Professor, Dept. of General Medicine, Govt KAPV Medical College, Tiruchirapalli, India

\section{Abstract}

A prospective study was carried out to find the percentage of dyslipidemia in type II diabetics in comparison with non diabetic individuals, to study the pattern of dyslipidemia, categorize the levels of LDL, HDL and triglycerides into higher, borderline and lower risk of developing coronary heart disease in type II diabetics and categorize the type of and level of dyslipidemia in symptomatic and asymptomatic coronary artery disease.

\section{Introduction}

In newly diagnosed, middle-aged patients with type 2 diabetes, the same group found that the incidence of cardiovascular mortality increased with rising fasting plasma glucose (FPG) at baseline during a 10-year study. In all patients, irrespective of treatment mode this association was found. A high FPG level significantly predicted cardiovascular mortality independent of other risk factors in multiple regression analysis ${ }^{19}$. As hyperglycemia alone does not explain all the increased risk for CHD in people with type 2 diabetes, other factors must be considered. It has been postulated that rather than being a complication of DM, CHD and DM share common genetic and environmental antecedents. They have in common many CHD risk factors, and a possible link between them is insulin resistance syndrome. Compared with the non diabetic population the prevalence of dyslipidemia, obesity and sedentary lifestyle is higher in people with type 2 diabetes.

People with diabetes tend to have higher lowdensity lipoprotein (LDL) cholesterol and triglycerides and lower HDL. In them LDL particles tend to be smaller and denser, and this increases the risk for atherosclerosis.

Even at concentrations well below the National Cholesterol Education Program target of 130 $\mathrm{mg} / \mathrm{dl}, \mathrm{LDL}$ cholesterol is a strong independent predictor of coronary heart disease in individuals with diabetes, even when components of diabetic dyslipidemia are present. These results support recent recommendations for aggressive control of LDL, cholesterol in diabetic individuals, with a target level of $<100 \mathrm{mg} / \mathrm{dl}^{21}$ 


\section{Materials and Methods}

100 type II diabetes mellitus and 50 age, sex and BMI matched non diabetic individuals were studied. The labeling of dyslipidemia and the categorization of risk for developing coronary heart disease (CHD) was done according to guidelines of American diabetes association.

\section{Results and Discussion}

Out of 50 type 2 diabetics in LDL class almost more than half $(68 \%)$ fell in the higher risk group (LDL > $130 \mathrm{mg} \%$ ) of developing CHD. These are the patients who require pharmacological intervention at the outset as diet, exercise, behavioral modification and glycemic control alone cannot reduce LDL more than 15-25 mg\%' The prime aim is to achieve absolute reduction of LDL to less than $100 \mathrm{mg} \%$ and not the percentage reduction in LDL levels. 30 percent fell in the borderline group (LDL 100- $130 \mathrm{mg} \%$ ) who may require drug therapy preceded by or with behavioral modification simultaneously and only two percent fell in lower risk (LDL $<100 \mathrm{mg} \%)$ who should be monitored yearly for any increase in lipid levels. Thus, LDL hyperlipoprotienemia was the major dyslipidemia observed in dangerously high levels in type 2 diabetic patients.

Table 1: Distribution of the study population based on the BMI

\begin{tabular}{|l|c|c|c|}
\hline BMI & Type II DM & Controls & \multirow{2}{*}{ P value } \\
\hline 18.5- 24.9 & $11(22 \%)$ & $15(30 \%)$ & \multirow{2}{*}{0718} \\
\cline { 1 - 3 } $\mathbf{2 5 - 3 0}$ & $36(72 \%)$ & $30(60 \%)$ & \\
\cline { 1 - 3 } 30.1 - 34.9 & $3(6 \%)$ & $5(10 \%)$ & \\
\cline { 1 - 3 } Total & $50(100 \%)$ & $50(100 \%)$ & \\
\cline { 1 - 3 } Mean + SD & $28.45 \pm 2.15$ & $26.7 \pm 2.04$ & \\
\hline
\end{tabular}

$\mathrm{P}$ value derived by applying student $\mathrm{t}$ test

Table 10 shows the distribution of the study population based on the BMI. It is seen from the table that the majority of the study subjects in both the groups were in the BMI group between 25 and
30 and there is no statistical significant difference in BMI between the two groups and it proves that $\mathrm{BMI}$ is not an independent risk factor for diabetes.

Fig 1: Distribution of the study population based on the BMI

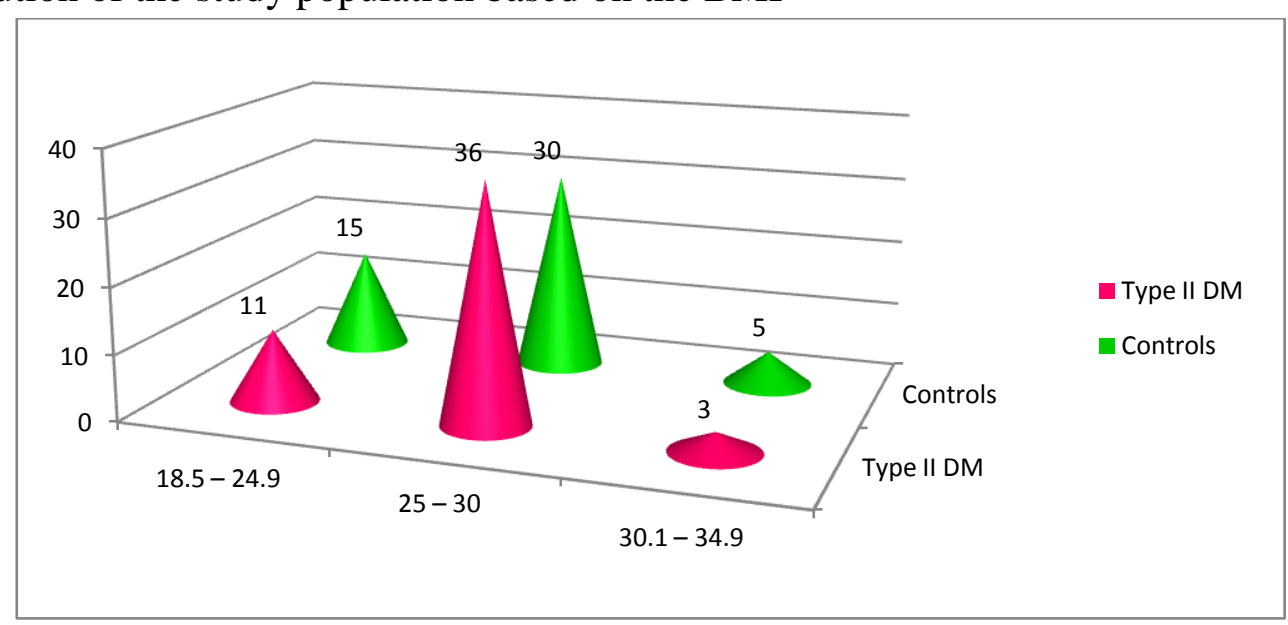

Table 2: Mean and SD of the blood pressure between the two groups

\begin{tabular}{|l|c|c|c|}
\hline Blood pressure & $\begin{array}{c}\text { Type II DM } \\
(\text { mean } \pm \text { SD) }\end{array}$ & $\begin{array}{c}\text { Controls } \\
(\text { mean } \pm \text { SD) }\end{array}$ & P value \\
\hline Systolic BP & $143.2 \pm 20.6$ & $129.1 \pm 10.5$ & $<.001$ \\
\hline Diastolic BP & $87.1 \pm 11.9$ & $78.5 \pm 8.4$ & $<.001$ \\
\hline
\end{tabular}

$\mathrm{P}$ value derived by student $\mathrm{T}$ test 


\section{JMSCR Vol||07||Issue||03||Page 1298-1305||March}

Table 2 shows the Mean and SD of the blood pressure between the two groups. It is inferred from the table that the mean systolic and diastolic
BP in the type II diabetes group was much more higher than the control group and the difference was found to be statistically significant $(\mathrm{p}<.05)$.

Fig 2: Mean and SD of the blood pressure between the two groups

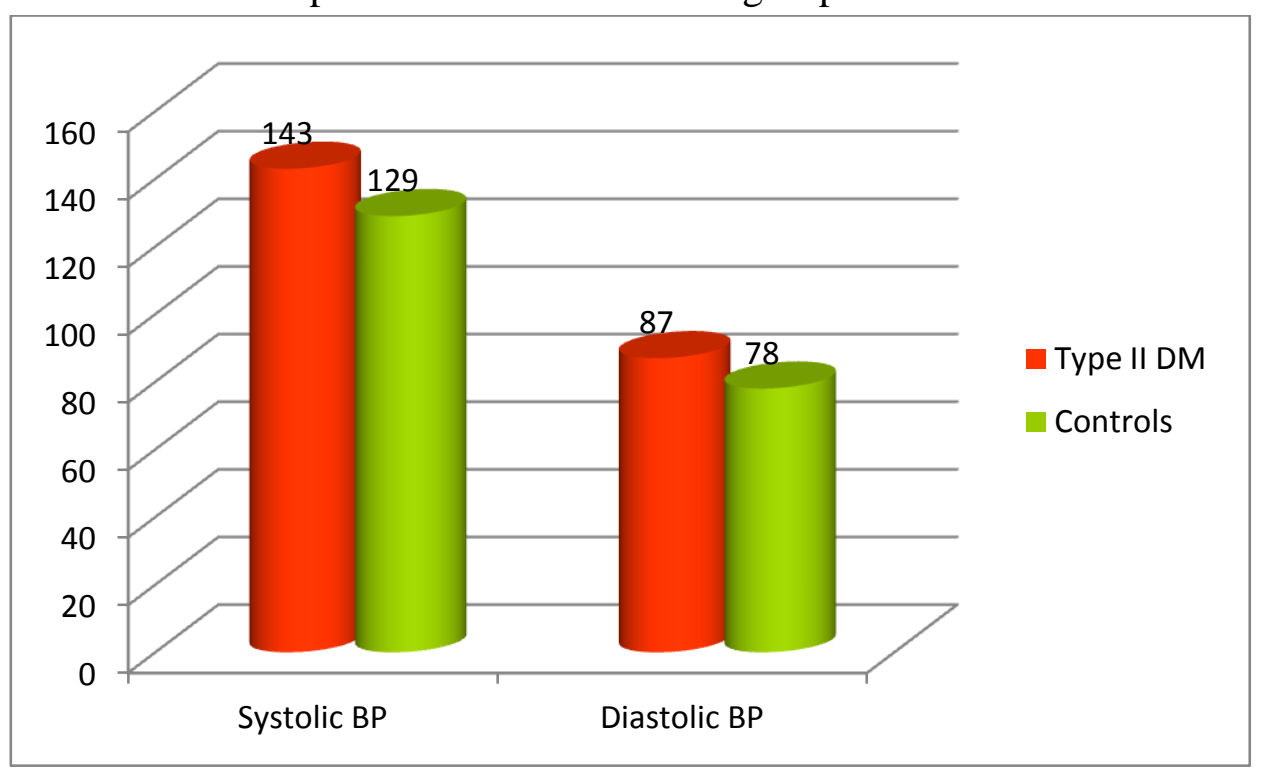

Table 3: Mean and SD of fasting and post-prandial blood sugar between the two groups

\begin{tabular}{|l|c|c|c|}
\hline Blood glucose & $\begin{array}{c}\text { Type II DM } \\
(\text { mean } \pm \text { SD) }\end{array}$ & $\begin{array}{c}\text { Controls } \\
(\text { mean } \pm \text { SD) }\end{array}$ & P value \\
\hline Fasting & $151.4 \pm 18.9$ & $95.4 \pm 15.5$ & $<.001$ \\
\hline Post-prandial & $260 \pm 39.5$ & $141.6 \pm 22.6$ & $<.001$ \\
\hline
\end{tabular}

$\mathrm{P}$ value derived by student $\mathrm{T}$ test

Table 3 shows the Mean and SD of fasting and post-prandial blood sugar between the two groups. It is inferred from the table that that the fasting higher among the diabetes group than the control group and the difference was found to be and post-prandial blood glucose levels are much statistically significant $(\mathrm{p}<.05)$.

Fig 3: Mean and SD of fasting and post-prandial blood sugar between the two groups

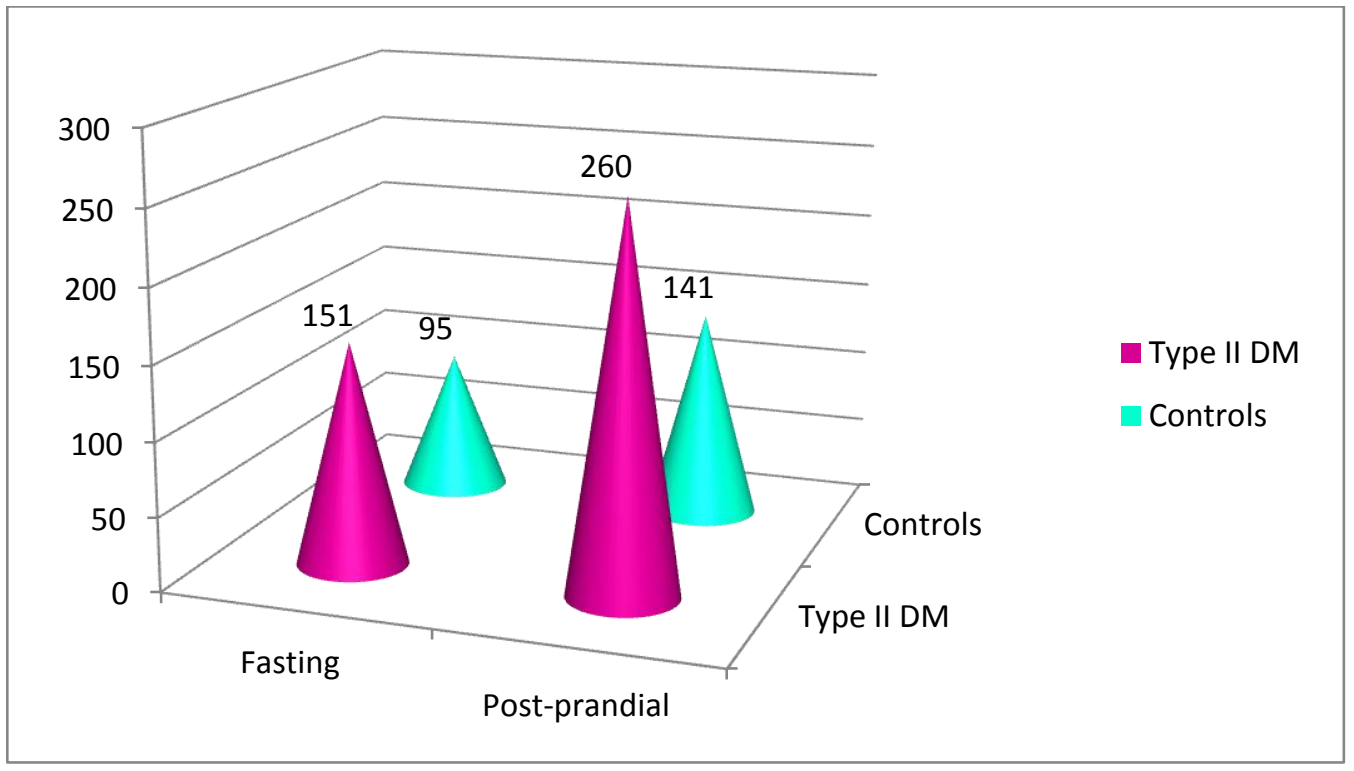


Table 4: Distribution of the study population based on the ECG findings

\begin{tabular}{|l|c|c|c|}
\hline ECG findings & Type II DM & Controls & P value \\
\hline Abnormal & $35(70 \%)$ & $4(8 \%)$ & \multirow{2}{*}{$<.001$} \\
\cline { 1 - 3 } Normal & $15(30 \%)$ & $46(92 \%)$ & \\
\cline { 1 - 3 } Total & $50(100 \%)$ & $50(100 \%)$ & \\
\cline { 1 - 3 } & &
\end{tabular}

$\mathrm{P}$ value derived by applying chi-square test

Table 4 shows the distribution of the study population based on the ECG findings. The most common ECG abnormalities which were present in our study subjects were old inferior wall MI, anterior wall MI or lateral wall MI and few patients had chronic stable ischemia and all these abnormalities were present in $70 \%$ of the patients with type II DM and among the control group only $8 \%$ had these abnormalities and the difference was found to be statistically significant $(\mathrm{p}<.05)$.

Fig 4: Distribution of the study population based on the ECG findings

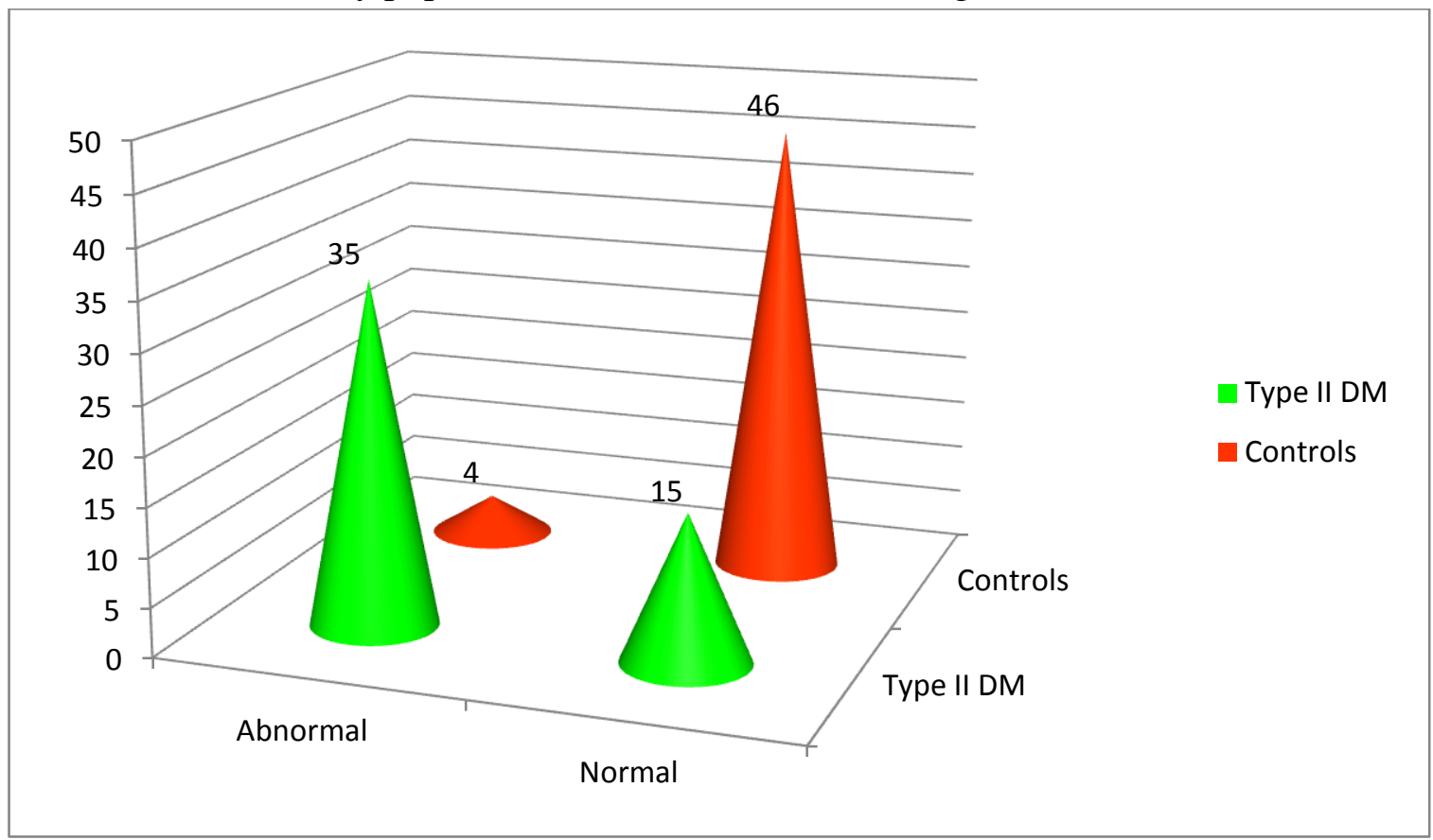

Table 5: Mean and SD of the lipid parameters between the two groups

\begin{tabular}{|l|c|c|c|}
\hline Lipid parameter & $\begin{array}{c}\text { Type II DM } \\
\text { (mean } \pm \text { SD) }\end{array}$ & $\begin{array}{c}\text { Controls } \\
\text { (mean } \pm \text { SD) }\end{array}$ & P value \\
\hline HDL & $40.3 \pm 5.5$ & $49 \pm 6.4$ & $<.001$ \\
\hline LDL & $159.7 \pm 33.7$ & $101.4 \pm 29.6$ & $<.001$ \\
\hline Total cholesterol & $203.4 \pm 26.5$ & $162 \pm 21.5$ & $<.001$ \\
\hline Triglycerides & $255.4 \pm 34.9$ & $152.5 \pm 30.6$ & $<.001$ \\
\hline VLDL & $59.7 \pm 18.8$ & $29.6 \pm 15.5$ & $<.001$ \\
\hline
\end{tabular}

$\mathrm{P}$ value derived by student $\mathrm{T}$ test

Table 5 shows the Mean and SD of the lipid parameters between the two groups. It is inferred from the table that the LDL, total cholesterol, triglycerides and VLDL were higher among the diabetes group than that of the control group and similarly the HDL cholesterol was higher in the control group than the diabetes group and this difference was found to be statistically significant $(\mathrm{p}<.05)$. 
Fig 5: Mean and SD of the lipid parameters between the two groups

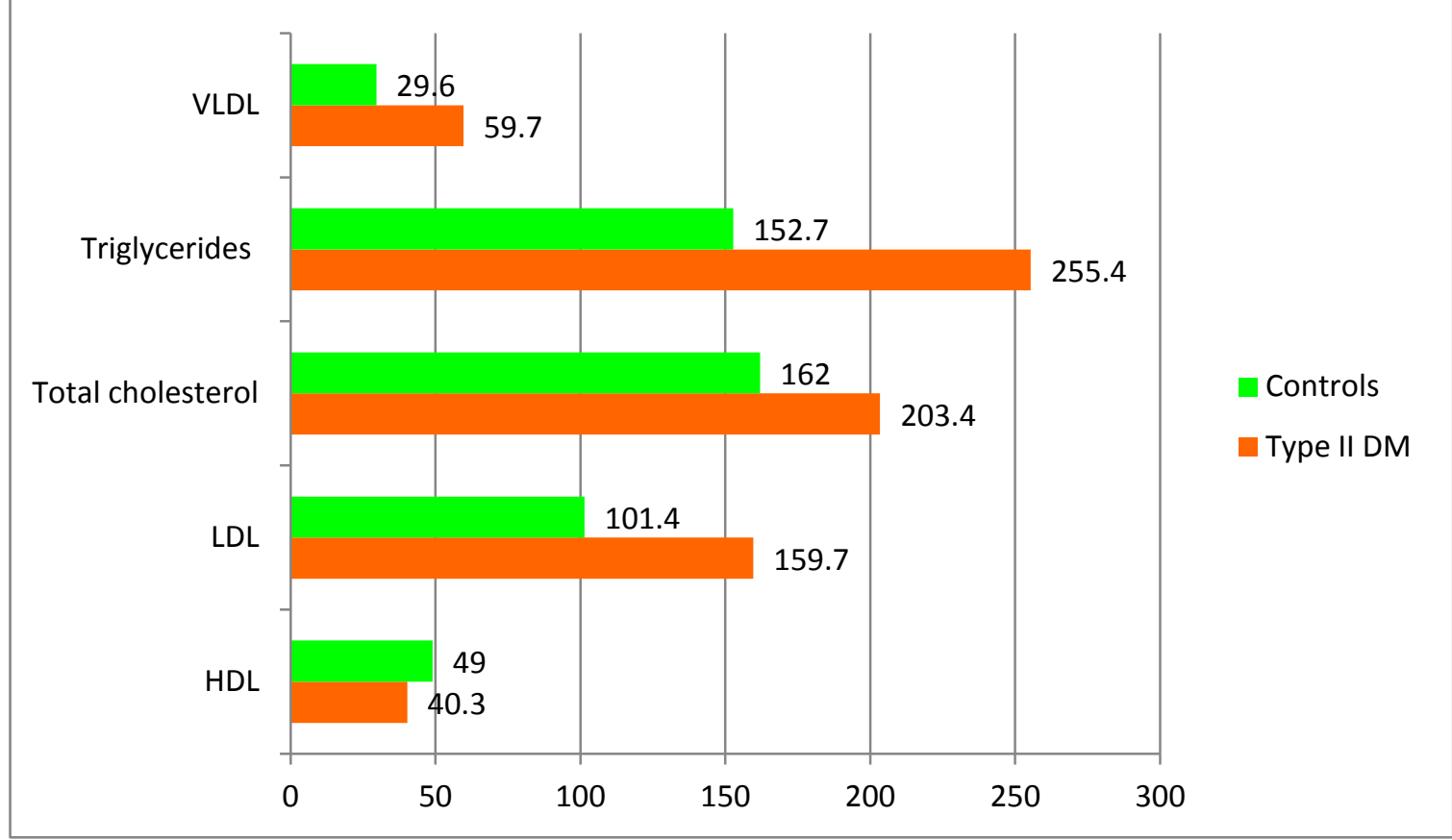

Table 6: Association between LDL cholesterol levels and IHD among the study subjects

\begin{tabular}{|l|c|c|c|c|c|}
\hline \multirow{2}{*}{$\begin{array}{l}\text { LDL cholesterol } \\
\text { levels }\end{array}$} & \multicolumn{2}{|c|}{ Type II DM } & \multicolumn{2}{c|}{ Controls } & \multirow{2}{*}{ P value } \\
\cline { 2 - 5 } & CAD present & CAD absent & CAD present & CAD absent & \\
\hline$<\mathbf{1 3 0}$ & $2(6 \%)$ & $14(93.3 \%)$ & 0 & $43(93.4 \%)$ & \multirow{2}{*}{$<.001$} \\
\hline$>\mathbf{1 3 0}$ & $33(94 \%)$ & $1(6.6 \%)$ & $4(100 \%)$ & $3(6.6 \%)$ & \\
\hline Total & $35(100 \%)$ & $15(100 \%)$ & $4(100 \%)$ & $46(100 \%)$ & \\
\hline
\end{tabular}

$\mathrm{P}$ value derived by applying chi-square test

Table 6 shows the association between LDL common among people with LDL levels more cholesterol levels and IHD among the study subjects. It is inferred from the table that the prevalence of ischemic heart diseases was more than $130 \mathrm{mgs} / \mathrm{dl}$ among the diabetic patients than the control group and this difference was found to be statistically significant $(\mathrm{p}<.05)$.

Fig 6: Association between LDL cholesterol levels and IHD among the study subjects

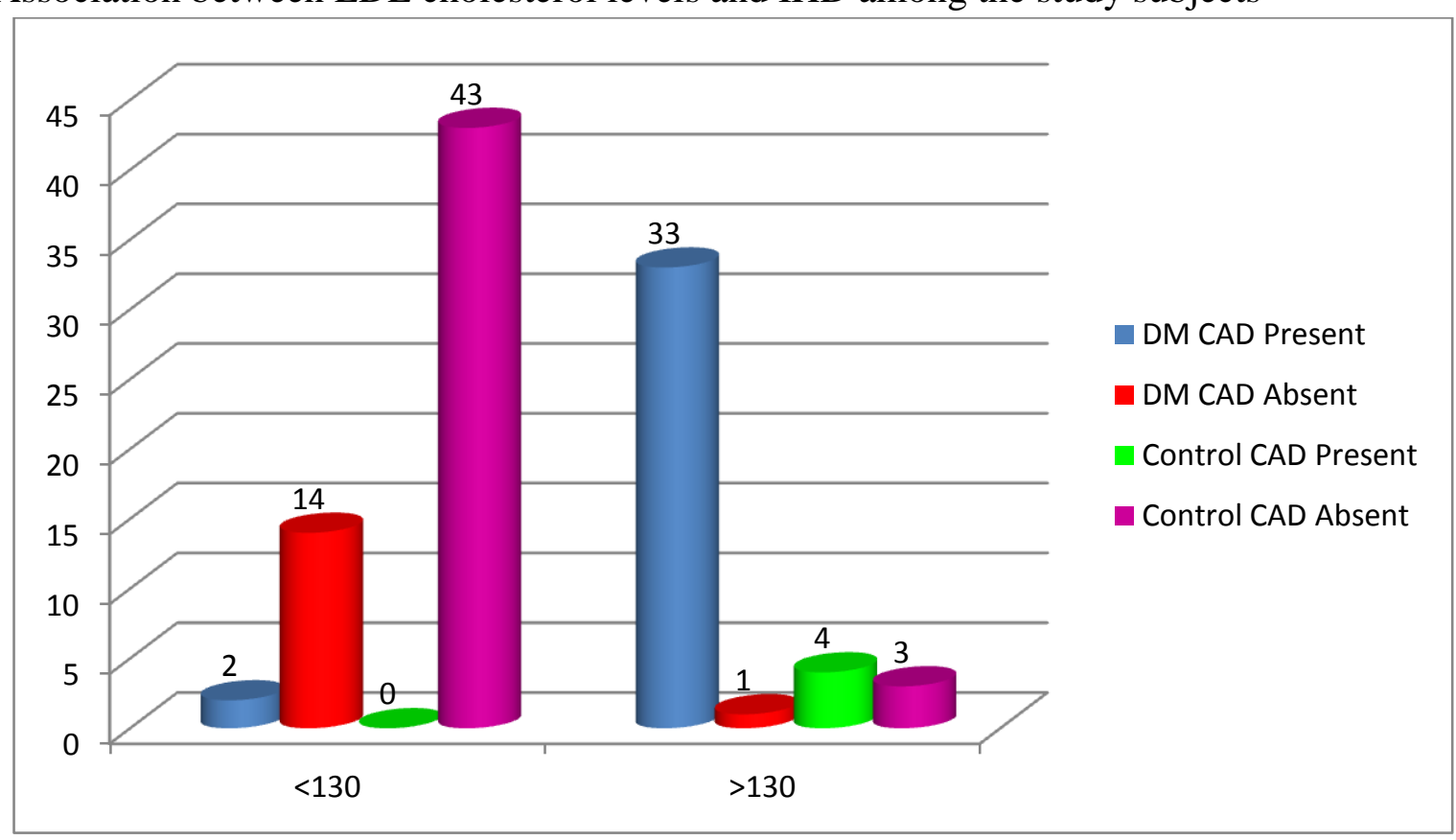


Table 7: Association between LDL levels and Risk of CAD

\begin{tabular}{|l|c|c|}
\hline LDL level /Risk & No of persons & Percentage \\
\hline$>130 /$ high & 34 & 68 \\
\hline $100-130 /$ Borderline & 15 & 30 \\
\hline$<100 /$ Low & 1 & 2 \\
\hline
\end{tabular}

Fig 7: Association between LDL levels and Risk of CAD

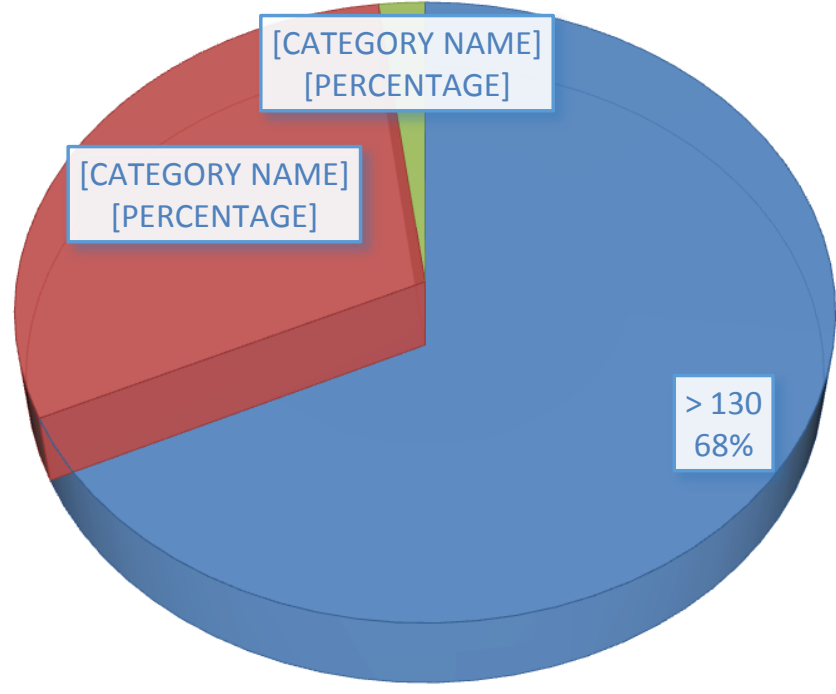

\section{Discussion}

The present study consisted of 50 patients of type diabetes who were either known cases, already on treatment or freshly diagnosed attending either the OPD or diabetic clinic or admitted were studied for the prevalence of dyslipidemia and assessment of coronary risk by detailed history, clinical examination investigations, ECG. A control group of 50 non diabetic healthy individuals were taken and compared.

In this study group patients whose type and level of dyslipidemia was compared to assess the severity of CHD risk, also their ECG compared to confirm the propensity of underlying dyslipidemia leading to coronary heart disease.

An interestingly high percentage of dyslipidemia $(100 \%)$ has been found in type 2 diabetic in the present study as compared to the western data (60$80 \%)$. The major concern which this study highlights is the percentage $(78.5 \%)$ of LDL dyslipidemia which is similar to western data (60$80 \%)$ while hypertriglyceridemia (>200mg/dl) was seen in $42 \%$ (compare PROCAM study, $39 \%)$. Low HDL $(<35 \mathrm{mg} / \mathrm{dl})$ was present in $32 \%$ patients (PROCAM study, 27\%).

When the group was compared, LDL dyslipidemia emerged as the deciding factor with $68 \%$ falling at high risk for CHD (LDL>130mg/dl) patients.

The UKPDS 23 study $^{74}$ showed that the coronary artery disease was significantly associated with increased concentration of low density lipoproteins decreased high density lipoprotein concentrations and increased concentration of triglycerides.

In the san antonia heart study $(1998)^{71}$ the median TG level was $200 \mathrm{mg} \%$ and $<5 \%$ of diabetic women and $15 \%$ of diabetic men had TG levels $>400 \mathrm{mg} \%$ whereas in the present study 5\% patients had TG $>400 \mathrm{mg} \%$ the median LDL cholesterol level LDL was 130-140 $\mathrm{mg} \%$ and only $25 \%$ of subjects had an LDL cholesterol level $>155 \mathrm{mg} \%$ whereas in this study $28.5 \%$ had LDL cholesterol level $>155 \mathrm{mg} \%$ whereas in this study $28.5 \%$ had LDL $>155 \mathrm{mg} \%$ 
In indian studies udawat el al (2001) ${ }^{55}$ reported dyslipidemia in $89 \%$ of type 2 diabetic patients LDL hyperlipoproteinemia (LDL>100 $\mathrm{mg} \%$ ) in $76 \%$, HDL dyslipedemia (HDL $<35 \mathrm{mg} \%$ ) in $58 \%$, hypertriglyceridemia (TG>200mg\%) in $22 \%$ patients on analyzing CHD risk based on lipid profile it was revealed that in LDL moiety $68 \%$ fell in higher of risk of CHD (LDL > $130 \mathrm{mg} \%$ ), $30 \%$ in borderline risk ( LDL 100-30 mg\%), and $2 \%(\mathrm{LDL}<100 \mathrm{mg} \%)$ in lower risk. For HDL $18.5 \%$ fell in higher risk (HDL <35mg \%) and TG only $0.5 \%$ fell in higher risk (TG $>400 \mathrm{mg} \%$ ). The lipid profile was significantly altered in diabetics patient as compared to non diabetics .

Kodali et al $(1991)^{81}$ reported prevalence of hyper lipidemia in $34 \%$ of type 2 diabetics subjects where hyperlipidemia was labeled when total cholesterol was $>275 \mathrm{mg} \%$ and / or triglyceride > $175 \mathrm{mg} \%$

Walia et (1999) ${ }^{70}$ observed hypercholesterolemia in $43.6 \%$ hypercholesterolemia in 43.6 hypertriglyceridemia in $52.5 \%$ HDL dyslipidemia in $42 \%$ and LDL dyslipidemia in $29.9 \%$ where dyslipidemia was labeled when total cholesterol $>200 \mathrm{mg} \%, \mathrm{HDL}<40 \mathrm{mg}, \mathrm{TG}>150 \mathrm{mg}$ $\%$ and LDL $>140 \mathrm{mg} \%$ the difference between present study and the above two studies is probably due to the different cut of values taken for labeling dyslipidemia.

The earlier Indian studies have also compared the lipid profile in diabetics and non diabetics bhu et al $(1998)^{82}$ observed higher levels of cholesterol and LDL in diabetics whereas hardas et al $(1991)^{83}$ found only higher TG levels in diabetics

However in the present study higher total cholesterol, TG, LDL and lower HDL levels where seen in diabetics and the comparison was statistically significant

\section{Conclusion}

Out of 50 type 2 diabetics in LDL class almost more than half $(68 \%)$ fell in the higher risk group (LDL > $130 \mathrm{mg} \%$ ) of developing CHD. These are the patients who require pharmacological intervention at the outset as diet, exercise, behavioral modification and glycemic control alone cannot reduce LDL more than $15-25 \mathrm{mg} \%{ }^{78}$ The prime aim is to achieve absolute reduction of LDL to less than $100 \mathrm{mg} \%$ and not the percentage reduction in LDL levels. 30 percent fell in the borderline group (LDL 100- $130 \mathrm{mg} \%$ ) who may require drug therapy preceded by or with behavioral modification simultaneously and only two percent fell in lower risk (LDL $<100 \mathrm{mg} \%$ ) who should be monitored yearly for any increase in lipid levels. Thus, LDL hyperlipoprotienemia was the major dyslipidemia observed in dangerously high levels in type 2 diabetic patients. LDL dyslipidemia is more significant from prognostic and therapeutic point of view hence preference should be given to reduction of LDL by pharmacotherapy in form of statins as first choice followed by HDL and then Triglycerides. This is at variance to the earlier held view where high TG and low HDL have been identified as major risk factors in the majority of cases ${ }^{55}$.

\section{References}

1. Richard WN, Stuart WZ, Richard WJ, Mansoor K. Heart disease in diabetes. In Ronald CK. Gordon CW (Eds), Joslin Diabetes mellitus 13th ed. Philadelphia, Lea and Febiger 1994; 836-57.

2. Kannel WB, McGee DL. -Diabetes and glucose tolerance as risk ' factors for cardiovascular disease : The Framingham Study. Diabetes Care 1979; 2: 120-126.

3. Wingard DL, Barrett-Connor E. Heart disease and diabetes. In : National Diabetes Data Group. Diabetes in America. 2nd ed. Washington, D.C.: Government Printing Office, 1995 : 42948.

4. Pyorala K, Laakso $M$, Uusitupa $M$. Diabetes and atherosclerosis: An Epidemiologic view. Diabetes Metab Rev 1987; 3:463-524.

5. Stamler J, Vaccaro 0, Neaton JD, Wentworth D. Diabetes, other risk factors, and 12-yr cardiovascular mortality for men 
screened in the Multiple Risk Factor Intervention Trial. Diabetes Care 1993; 16 : 434-444.

6. Pekkanen .1, Linn S, Heiss G. Ten-year mortality from cardiovascular disease in relation to cholesterol level among men with and without preexisting cardiovascular disease. N Engl J Med 1990 ; 322: 1700-1707.

7. Rosengren A, Hagman M, Wedel 14, Wilhelmsen L. Serum cholesterol and long-term prognosis in middle-aged men with myocardial infarction and angina pectoris: a 16-year follow-up of the Primary Prevention Study in Goteborg, Sweden. Eur Heart J 1997 ; 18 : 754-761.

8. Rosengren A, We-lin L, Tsipogianni A, Wilholmsen L. Impact of cardiovascular risk factors on coronary heart disease and mortality among middle aged diabetic men: a general population study. BM,' 1989 ; 299: 1127-1131

9. Expert Panel on Detection, Evaluation, and Treatment of High Blood Cholesterol in Adults. Summary of the second report of the National Cholesterol Education Program (NCEP) Expert Panel on Detection, Evaluation, and Treatment of High Blood Cholesterol in Adults (Adult Treatment Panel II). JAMA 1993 ; 209 : 3015-3023.

10. American Diabetes Association. Management of dyslipidemia in adults with diabetes. Diabetes Care 1998 ; 21 : 179-182

11. Miettinen H, Lehto S, Salomaa VV. Impact of diabetes on mortality after the first myocardial infarction. Diabetes Care $1998 ; 21: 69-75$
12. Steven. M. Haffner, SeppoLehto -,Tapani Ronnemaa. Mortality from Coronary heart disease in Subjects with Type 2 Diabetes and in Non Diabetic Subjects with and without Prior Myocardial Infarction. NEJM 1998 ; 339: 229- 234

13. Pyorala K, Pedersen TR, Kjekshus J, Faergeman 0, Olsson AG, Thorgeirsson G. Cholesterol lowering with simvastatin improves prognosis of diabetic patients with coronary heart disease: a subgroup analysis of the Scandinavian Simvastatin Survival Study (4S). Diabetes Care 1997 ; $20: 614-620$

14. Sacks FM, Pfeffer MA, Moye LA. The effect of pravastatin on coronary events after myocardial infarction in patients with average cholesterol levels. N Engl Med 1996 ; 335: 1001-1009

15. Abbott RD, Donahue RP, Kannel WB, Wilson PW. The impact of diabetes on survival following myocardial infarction in men vs. women: the Framingham Study. JAMA $1988 ; 260: 3456-3460$. 